\title{
O ESPAÇO dA CELEBRAÇÃo EM TEMPOS DE ISOLAMENTO SOCIAL
}

\author{
Ms. Ir. Penha Carpanedo* \\ DOI: https://doi.org/10.52451/teopraxis.v37i129.12 \\ Recebido: 23 de janeiro de 2019 | Aprovado: 26 de maio de 2019
}

Resumo: A casa onde moramos, desponta como lugar seguro em tempo de isolamento social. Mas ela é, por tradição, um espaço eclesial que abriga a Igreja doméstica e sua liturgia. No centro da casa está a mesa da comunhão diária, sustentada pela partilha da refeição, pela convivência, pela memória das tantas refeições que Jesus fez com os seus.

Palavras-chave: Casa. Isolamento. Reunião. Mesa. Escuta. Prece.

\section{A casa como lugar seguro}

Estamos no meio de uma crise sanitária sem precedentes, agravada por um desgoverno que nega os possíveis e necessários cuidados, colocando-nos em extrema dificuldade, sobretudo os pobres que não dispõem de recursos mínimos para manter-se em isolamento. É uma situação que, de alguma forma, atinge todas e todos nós. Em cinco meses chegamos ao alarmante número de cem mil vidas ceifadas, nomes apagados, histórias interrompidas, entre as quais figuram rostos de pessoas conhecidas, de parentes e de tantos amigos e amigas. E em meio a este luto coletivo a instabilidade continua, com a situação econômica e política piorada, sem qualquer certeza de solução num futuro próximo.

Mas os sábios dizem que nunca se deve desperdiçar uma crise. Sem escamotear a crise, podemos fazer dela uma fonte de transformação. A história nos ensina que é possível renascer das

* Pertence às Pias Discípulas do Divino Mestre. Redatora da Revista de Liturgia. Membro da Rede Celebra de animação litúrgica. Mestre em Liturgia. email: redacao@revistadeliturgia.com.br 
cinzas. Há quem diga, que depois desta dramática experiência não seremos mais os mesmos, as mesmas, que o mundo terá que ser reinventado desde a forma de gerenciar a economia até os modos de viver dentro de nossas casas.

$\mathrm{Na}$ Igreja vivemos a impossibilidade de nos reunir presencialmente para as diversas atividades pastorais, gritando mais forte o fato de não podermos participar plenamente da Eucaristia. Talvez, as alternativas que surgiram para suprir esta privação, estejam revelando, quão limitada é a nossa compreensão da ceia memorial do Senhor e isso deverá nos levar a buscar o sentido mais profundo da eucaristia que inclui o lava-pés do serviço e do amor fraterno. Aliás, estamos tendo a oportunidade de contemplar a entrega do Senhor, no trabalho arriscado de tantos profissionais da saúde, na luta para obter o auxilio emergencial, na partilha e na solidariedade em socorrer os mais frágeis, na batalha cotidiana pela sobrevivência em condições adversas.

E enquanto a instabilidade permanece a palavra de ordem é ficar em casa para não contrair nem contribuir para disseminar o vírus. Ninguém deve se arriscar, nem mesmo para ir à Igreja. A fé pode ser cultivada e celebrada em casa. Este espaço pequeno, tão pouco importante aos olhos de quem faz os grandes relatos da história, pouco significativo para a economia e para a politica, de repente vem à tona como o lugar seguro e se revela como espaço simbólico, eclesial e litúrgico. Isso de voltar para a casa, remete ao tempo de Jesus e das primeiras comunidades cristãs, que tinha a casa como lugar de reunião e de evangelização.

\section{A casa da Igreja}

Jesus foi um rabino itinerante, missionário. Com ele caminhavam os doze, outros discípulos, um grupo de mulheres (Lc 8,1-3; Mc 15,40s). Em suas andanças parava nas casas que o 
recebiam oferecendo abrigo, alimento, aconchego. Jesus falava às multidões, mas era na casa que Ele conversava com os discípulos e discípulas na intimidade. A palavra casa nos evangelhos é quase sempre uma referência ao lugar onde Jesus se encontrava com os seus discípulos e discípulas e os formava (cf. Mc 1,17; 9,28). A última ceia de Jesus foi celebrada numa casa (Mc 14,15) e foi na casa que depois de sua ressurreição Ele apareceu aos 11 quando estavam à mesa [Mc 16,14-18] ou quando estavam reunidos com as portas fechadas (Jo 20,19). A casa extrapola a família natural. Jesus deixa claro, que a sua família, sua mãe e seus irmãos "são aqueles que ouvem a palavra de Deus e a põem em prática" (Lc 11,28).

Essas casas certamente se tornaram referências para as comunidades cristãs depois da ressurreição. Imaginemos, por exemplo, a casa de Marta, Maria e Lázaro, em Betânia, onde Jesus tantas vezes se hospedou a caminho de Jerusalém (cf. Lc 10,38-42); ou a casa de Pedro em Cafarnaum onde Jesus morava (cf. Mc 1,2; 3,20). Nas comunidades de Paulo são conhecidas as casas de Lídia que acolheu Paulo e onde a Igreja se reunia (cf. At 16,14-15); também a casa de Prisca e Áquila um casal importante na itinerância missionária de Paulo, que abriu a sua casa para o apóstolo e na qual a comunidade cristã se reunia regularmente (cf. 1Cor 16,19). Em Jerusalém, podemos lembrar a casa de Maria mãe de João Marcos para onde Pedro se dirigiu depois da sua libertação milagrosa (At 12,12-16). A Igreja de Jerusalém se reunia nas casas e também no templo, tão importante para o povo de Israel como lugar de revelação: "em suas casas partiam o pão, compartilhavam a comida com alegria e simplicidade de coração (At 42,46).

Estas casas cedidas para servir de lugar de reunião da comunidade, passavam por uma adequação em função do número de pessoas e das ações que ali se realizavam. Sem perder a fisionomia da casa abria-se o necessário espaço para abrigar a comunidade. Não se tinha a intenção de criar um espaço 
sagrado, pois sagrada era a comunidade reunida, ela mesma lugar da manifestação do Ressuscitado. A mais antiga Casaigreja de que se tem notícia, situada na atual Síria, numa cidade de nome Dura Europos, era uma residência familiar que foi ampliada para prestar este serviço.

Com o tempo a Igreja foi se estruturando e grandes templos foram construídos, à medida que a própria Igreja e a sua liturgia vão se modificando sob o domínio do clero, praticamente sem participação do povo e sem ministérios leigos. Quanto mais o povo deixa de ser sujeito e a liturgia já não se configura como uma ação comunitária da fé, mais o espaço da celebração passa a atender à necessidade de olhar, em vez de participar ativamente.

Com o movimento de volta às fontes do Concilio Vaticano II, reabilitando o modelo de Igreja povo de Deus, caminhos se abriram para as pequenas comunidades. Foi uma verdadeira revolução do ponto de vista eclesial e litúrgico, em que o povo passa a ser sujeito eclesial e sujeito também da ação litúrgica. Aqui na América Latina, a recepção do Concílio, sobretudo a partir de Medellín, criou espaço para uma experiência concreta da Igreja povo de Deus nas Comunidades Eclesiais da Base, que se reúnem em pequenos grupos, muitas vezes nas casas, num salão comunitário, em espaços mais simples, em movimento circular. Contudo não é fácil em 50 anos, passar de um modelo milenar, para um novo jeito de ser Igreja. Há sempre a tendência de voltar ao velho sistema.

\section{A volta pra casa}

Com o isolamento social veio à tona uma avalanche de missas com o padre, mas sem o povo, oferecida via mídia e recebida como resposta satisfatória por grande parte do povo católico. No entanto, boa parte dos fiéis tem se perguntado se em vez disto, não seria mais interessante reunir a família e fazer da pequena igreja da casa um lugar de encontro com Jesus 
conforme ele mesmo prometeu: "Onde dois ou três estiverem reunidos em meu nome, estarei no meio deles” (Mt 18,20).

Aliás, os fiéis nunca deixaram de fazer da casa, de alguma maneira, um lugar de viver e celebrar a fé. É muito comum encontrar nas casas, sobretudo dos pobres, um altarzinho, uma imagem, uma vela e a prática diária da oração, em geral, com expressões da piedade popular já que a liturgia se tornou inacessível ao povo. Daqui podemos começar a partir da herança de nossos pais e avós. Quantos e quantas de nós não se recorda do diminuto ofício cotidiano, da manhã e da noite, "com Deus me deito, com Deus me levanto, com a graça de Deus e o Divino Espírito Santo"?

Aos poucos podemos ir desenvolvendo uma liturgia doméstica, feita de pequenos ritos em estilo simples, presidida pela mãe ou por outra pessoa da família. Por esta celebração podemos alegrar-nos na presença de Jesus, escutar e meditar a sua palavra e, junto com Jesus, erguer ao Pai os nossos corações em preces, partilhar um pão em ação de graças, invocar uma benção. É uma liturgia que pode renovar a esperança e a confiança de que Deus não nos abandona, mesmo quando a morte nos ameaça.

A liturgia doméstica se adapta ao espaço da casa, buscando nela o melhor para se criar um círculo, seja na sala, ou numa varanda, ou num terraço, ou no quintal... Em qualquer caso, é importante cuidar que as pessoas estejam confortáveis e unidas entre si. Se for dentro de casa é importante estabelecer um ponto de referência que pode ser uma vela, a bíblia, um ícone ou a cruz, uma flor, sobre uma mesinha ou sobre um tecido posto no chão. Não se trata de transportar para a casa o modelo da igreja maior. Mas o espaço organizado e bonito, ainda que com toda a simplicidade, corresponde à linguagem própria da liturgia que expressa a fé por meio de sinais sensíveis (cf. SC 7).

$\mathrm{Na}$ casa, talvez o espaço mais sagrado, seja a mesa, onde todos se encontram para partilhar o pão, dom de Deus e fruto 
do trabalho de cada um, cada uma. Infelizmente já não é tão comum priorizar a refeição como lugar de convivência. A televisão, o celular, o trabalho nos capturam e indicam outra direção. Poderia ser este um bom começo, se não sempre, pelo menos de vez em quando: preparar uma boa comida, arrumar a mesa, alguém pode fazer uma prece de agradecimento a Deus pelo pão nosso de cada dia e pelo dom de estarmos juntos. Comer e beber na alegria e na comunhão tem enorme sentido espiritual. Recorda as tantas vezes que Jesus sentou-se com seus para comer e beber, em ação de graças, sinalizando a chegada do Reino.

Esta experiência forçada pela pandemia soa como alternativa, já que não podemos nos juntar à comunidade; ao mesmo tempo, aponta para um futuro, que já se faz presente, de uma Igreja que redescobre formas concretas de exercer o sacerdócio comum dos fiéis, na vida e na liturgia. Oxalá a experiência de celebrar no restrito ambiente da casa, nos devolva definitivamente o imprescindível da participação efetiva e ativa, e livre a Igreja de tratar o povo como mero espectador (Cf. SC 48).

\section{Referências Bibliográficas}

BÍBLIA SAGRADA. Tradução oficial da CNBB. Brasília: Ed. CNBB, 2018. DOCUMENTOS DO CONCÍLIO ECUMÊNICO VATICANO II. São Paulo: Paulus, 2014, 7aed. In: Constituição Sacrosanctum Concilium sobre a Sagrada Liturgia, p.33-79. 